Ręka Gabriela, Paprzycka Karolina, Piecewicz-Szczęsna Halina. The knowledge and the opinion of patients on the government package called 'fast oncological therapy' - a pilot survey study. Journal of Education, Health and Sport. 2020;10(7):98-104. eISSN 2391-8306. DOI http://dx.doi.org/10.12775/JEHS.2020.10.07.010

https://apcz.umk.pl/czasopisma/index.php/JEHS/article/view/JEHS.2020.10.07.010

https://zenodo.org/record/3950629

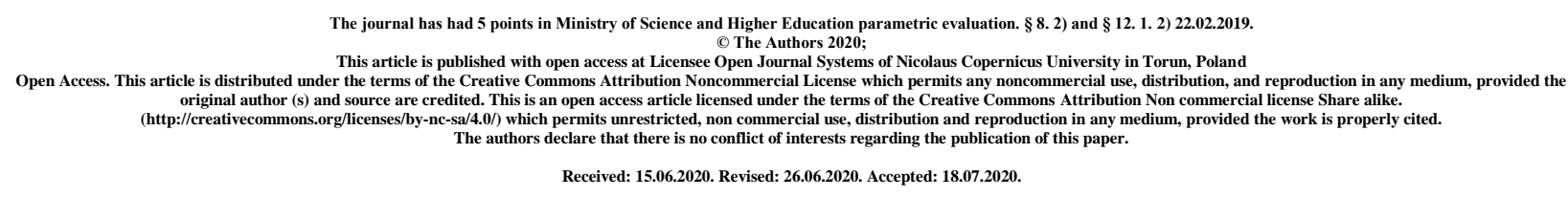

\title{
The knowledge and the opinion of patients on the government package called 'fast oncological therapy' - a pilot survey study
}

\author{
Gabriela Ręka, Karolina Paprzycka, Halina Piecewicz-Szczęsna
}

${ }^{1}$ Gabriela Ręka
gabrysia.reka@gmail.com
https://orcid.org/0000-0001-9728-5281

${ }^{1}$ Karolina Paprzycka

kpaprzyc007@interia.eu

https://orcid.org/0000-0001-7875-429X

${ }^{2}$ Halina Piecewicz-Szczęsna

halpiec@gmail.com

https://orcid.org/0000-0002-0573-7226

1 Students' Scientific Association of Chair and Department of Epidemiology and Clinical Research Methodology, Medical University of Lublin, Radziwiłłowska 11, 20-080 Lublin, Poland

2 Chair and Department of Epidemiology and Clinical Research Methodology, Medical University of Lublin, Radziwiłłowska 11, 20-080 Lublin, Poland 


\begin{abstract}
Introduction and purpose: The fast oncological therapy was introduced in 2015 by a set of legal arts called an oncology package. Its main assumption was to reduce malignant neoplasms by improving the availability of diagnostics and complex treatment. The aim of the study is to analyse the level of knowledge and to learn opinions of patients of the Center of Oncology of the Lublin Region on the fast oncological therapy.

Material and methods: Material used in the analysis is the results of survey conducted on a group of patients from different hospital departments. An original anonymous questionnaire with 25 open and closed questions was used. Out of 130 distributed questionnaires, 44 items were returned completed. The program used to perform the statistical analysis was Statistica PL 10.0 2011 StatSoft.

Results: The survey indicates that $43.2 \%$ of respondents have ever heard about fast oncological therapy, 27.3\% declare knowledge of the therapy's basic aims. In a detailed knowledge test 1 point was awarded for every right answer. A maximum of 11 points could be obtained, with the average score being 2.3 points. $22.7 \%$ of patients surveyed did not answer any question correctly. No relationship has been found between age, place of residence or duration of the disease and the level of knowledge about the fast oncological therapy. $36.4 \%$ of respondents admit that they have been treated in accordance with the fast oncological therapy, but most of those who did (75\%), evaluate its effect positively.
\end{abstract}

Conclusions: The patients' knowledge about the package is extremely low. Only a minority of respondents are aware of the package's existence. However, the patients judge the changes introduced by fast oncological therapy as positive.

Keywords: medical oncology; health legislation; health education

\title{
Introduction
}

The fast oncological therapy is an organizational solution which was introduced on 1st January 2015 by a set of legal arts called an oncology package. It was amended on 1st July 2017. Its main goal is to efficiently guide an oncological patient through all stages of diagnosis and treatment. The fast oncological therapy covers patients in whom doctors suspect or find a malignant tumour and patients undergoing oncological treatment [1]. In 2014, an increase in cancer incidence was observed (by about 4 thousand new cases) [2]. Cancer is the second leading cause of deaths in Poland and it caused 24\% deaths among women and $27 \%$ of deaths among men in 2014 [2]. The picture of cancer mortality rates in Poland, both in terms of their structure and time trends, is similar to the picture in other countries in the European Union [3]. Main assumptions of the oncology package seem to be reasonably thought out and well planned themselves. Introduction of the fast oncological therapy was an important decision which has created opportunities for quick diagnosis and treatment. Although it was supposed to accelerate and improve oncological treatment in Polish healthcare system, it received severe criticism [4]. 


\section{Purpose}

The aim of the study is to analyse the level of knowledge and to learn opinions of patients of the Center of Oncology of the Lublin Region St. Jana z Dukli on the fast oncological therapy.

\section{Material and methods}

The study was conducted in September and October 2018. Material used in the analysis is the results of survey conducted on a group of oncological patients from different hospital departments. An original anonymous questionnaire with 25 open and closed questions, both single and multiple-choice, was used. Questions were based on information from the official government website [1]. Out of 130 distributed questionnaires, 44 items were returned completed. The surveyed patients suffered from malignant tumours of various organs. The largest group of patients suffered from reproductive organ neoplasm (38.6\%). Then, there were neoplasm of the digestive system and urinary system or prostate gland (both $18.2 \%$ each), head and neck neoplasm (13.6\%) and breast neoplasm (11.4\%).

The program used to perform the statistical analysis was Statistica PL 10.02011 StatSoft. P-value $<0.05$ was considered statistically significant. The study group consists of respondents at the age from 28 to 78, the average age being 57.2 ( \pm 13.7 ). Among respondents, 2 people $(4.5 \%)$ did not provide the information about their place of residence, $31.8 \%$ live in a large city (over 100,000 inhabitants), $25 \%$ in a small city (less than 100,000) and $38.6 \%$ in the countryside. The average time from getting diagnosed with malignant tumour is 22.1 months (from 1 to 228 months), while the median in this case is only 6 months.

\section{Results}

A minority of patients have ever heard of the fast oncological therapy (43.2\%), even fewer declare knowledge of its main aims (27.3\%). Of the 12 people who answered affirmatively to the question: "Do you know what are the main assumptions of the fast oncological therapy?", 10 answered the open question: "If so, please name some of them." The patients gave the following answers: "Medical consultations, shortening the waiting time for an appointment, efficient diagnostics", "Earlier dates possible", "Quick diagnosis, implementation of treatment, possibility of healing", "Quick treatment coverage", "Registration without queue, faster access to a specialist doctor", "Quick diagnostics, quick surgery", "Quick treatment without queues", "Diagnostic tests without queuing ", "Fast detection and treatment of cancer patient and reduction of cancer connected mortality", "Cancer removal surgery, chemotherapy, radiation therapy". All the answers but the last one are correct. The fast oncological therapy does not include surgery or particular type of therapy itself.

Further, questions checking the patients' knowledge of the fast oncological therapy related to the following: who can be qualified for the therapy; are there age restrictions in access to it; who can fill in the special document called Oncology Diagnosis and Treatment Card (Karta Diagnostyki i Leczenia Onkologicznego - DiLO card) for oncological patients; does the National Health Fund pay for oncological diagnostics and treatment; what are the deadlines for performing diagnostic tests; does a patient have a coordinator of his or her treatment; does the fast oncological therapy 
cover preventive examinations for early detection of neoplasm; does the therapy provide you with the possibility to live in a hostel next to the hospital or do you need a referral to a specialist doctor if the DiLO card has already been filled in for you. In 11 questions (11 points that can be obtained) the average score is only 2.6 points, the median being 2 points. $22.7 \%$ of the patients did not give any correct answer. The best test result is 8 points. It was obtained only by one person (Table 1).

Table 1. Analysis of patients' knowledge about the fast oncological therapy, detailed results

\begin{tabular}{|c|c|c|}
\hline Points scored & $\begin{array}{c}\text { The numer of patients with a } \\
\text { score }\end{array}$ & Percent $(\boldsymbol{\%})$ \\
\hline 0 & 10 & 22.7 \\
\hline 1 & 6 & 13.6 \\
\hline 2 & 8 & 18.2 \\
\hline 3 & 4 & 9.1 \\
\hline 4 & 5 & 11.4 \\
\hline 5 & 7 & 15.9 \\
\hline 6 & 3 & 6.8 \\
\hline 8 & 1 & 2.3 \\
\hline
\end{tabular}

Only $36.4 \%$ of respondents (16 people) confirm they have been treated in accordance with the fast oncological therapy. These patients were requested to answer the following questions regarding their opinion of the fast oncological therapy. Among them the majority (75\%) assesses it positively and claims that the changes introduced by the oncology package are indeed beneficial. $18.8 \%$ maintains that it is partly so, partly not. In the mentioned groups the following were pointed out as the advantages of the program (in order from the most frequently marked). 93,8\% admit that they had no difficulties during diagnostics as a part of the fast oncological therapy. Merely one person assesses the package negatively. The person did not answer the open question on what kind of problems he or she had experienced. $86.7 \%$ believe that the issued card makes it easier to navigate in the new healthcare system. $75 \%$ indicate the possibility of earlier diagnosis and the same number of surveyed patients claims that the new solution leads to neoplasm mortality reduction. $62.5 \%$ say that queues to specialists are shrinking. 
The Pearson correlation test and the Spearman correlation test do not show a significant relationship between the age of patients and their knowledge of the oncological package and between the time since the beginning of a treatment and the patients' knowledge of the package (p-value >0,05). In the variance analysis test and the Kruskal-Wallis test no significant correlation has been found between the subjects' place of residence and their knowledge of the package ( $\mathrm{p}$-value $>0,05$ ). The Mann-Whitney test shows that people who have participated in the package have significantly more knowledge about it (p-value $<0,05$ ). The median score in the knowledge test for people who used the package is 4.5 points and those who did not is only 1 point (due to the detection of non-homogeneity of variance in the Levenea test, the MannWhitney test was used to test the relationship, not the T-student test).

\section{Discussion}

Out of 130 questionnaires spread among patients in the hospital only 44 (which is 33,8\%) were handed back. This weak response to the survey could be caused by poor health condition of respondents, their age or lack of willingness to answer. It is worth highlighting that questionnaires were handed in and collected by nurses. Probably patients did not feel obliged to complete the survey when they did not meet examiners themselves. For sure, there should be conducted a study in the future which will cover a larger study group. For instance, in the Oncology Center of Lublin region there are no patients suffering from pulmonary neoplasms, because they are treated in other hospitals. The fast oncological treatment is also dedicated for teenagers and younger children who suffer from oncological diseases. Future researches should include their or their parents' opinion to get more accurate results.

Respondents know little about the fast oncological therapy. Doctors who fill in the card for them or other health care workers should be obliged to provide patients with detailed information about the future course of their therapy and solutions provided by oncological package. The card can be written by general practitioners or other specialists in hospital or medical center [1]. Nowadays the Internet is one of the most popular sources of information. In 2018 84,2\% of Polish households had access to the Internet [5]. That is why there should be official, reliable websites and programs where interested patients could find essential information.

In Poland there have been only few researches regarding patients' opinions on functioning of the fast oncological therapy so far. In a recent study there is shown that patients were dissatisfied with the reforms including the waiting lists package and the oncological package [6]. It is said that patients have no trust in reform success [6]. Three indicators of changes were chosen: public satisfaction with healthcare, waiting times and number of health professionals [6]. However, not only does the study focus on patients' opinion of the fast oncological therapy, but also gathers their responses about Regional Sickness Funds the National Health Fund. 
In the report prepared in 2016 [4] a total of 506 respondents participated in the survey, and they were recruited from all 16 voivodeships of Poland. $88 \%$ of respondents indicate that they have ever heard of fast oncological therapy [4], which differs from the study in the Oncology Center of Lublin region. The source of information on oncology package most frequently mentioned are traditional media, like television, radio and press. The second and the third place take oncologist (18\% of indications) and family doctor (17\%). The official website of the package was used by $17 \%$ of respondents. $16 \%$ of patients who have received the card do not know whether their current treatment or diagnosis is carried out as part of the fast oncological treatment. $72 \%$ of people believe that the card was a helpful idea in the process of oncological diagnosis and treatment. In the opinion of $66 \%$ of the respondents, the oncology package should be continued, but the majority of these people also believe that some are necessary change [4]. These results are similar to results from the study in the Oncology Center of Lublin region.

In a research conducted in 2015 there have been proved that after the oncological package implementation the average waiting time in queues for diagnostics and treatment was significantly shortened [7]. The study confirms patients' feelings about shorter waiting time in queues.

\section{Conclusions}

Analysis of the above data suggests that some patients do not know that they are covered by the fast oncological therapy. Only a minority of the respondents (about 40\%) are aware of its existence. This results in poor scores in detailed questions checking the respondents' knowledge. It is worth mentioning that people declaring the use of the fast oncological therapy show a significantly greater knowledge of its goals than people who claim that they do not use it. In oncological patients' opinion the introduced changes have really positive effects. However, more information should be given to people concerned about their course of diagnosis and treatment and about their legal rights. Moreover, a widespread study concerning the topic should be conducted in the future, as a bigger study group is needed to obtain data that would be more representative for all oncological patients from the Lublin region. 


\section{References}

1. Ministry of Health. Fast oncological therapy - the official government website http://pakietonkologiczny.gov.pl/ (accessed on 4 November 2019)

2. Wojciechowska U, Olasek P, Czauderna K, Didkowska J. Cancer in Poland in 2014. Polish National Cancer Registry. Department of Epidemiology and Cancer Prevention. Warszawa. 2016. 3. Zatoński WA, Sulkowska U, Didkowska J. Kilka uwag o epidemiologii nowotworów w Polsce [Some comments about cancer epidemiology in Poland]. Nowotwory. Journal of Oncology 2015;65(3):179-196. DOI: 10.5603/NJO.2015.0041

4. Gałązka-Sobotka M, Twarowski A, Raciborski F, Dłutek A. Raport. Społeczny monitoring wdrażania i realizacji pakietu onkologicznego. [Report. Social monitoring of implementation and realization of oncology package]. Fundacja Wygrajmy Zdrowie. Warszawa. 2016. Polish http://www.oipip.gorzow.pl/index_pliki/akt/Raport_monitoring_web.pdf?fbclid=IwAR0LD6At6 pVjOWm8oXRD2y9wgDhVSsTWh2YMgsImbj64WMG-1E4w6L2Ouk4 (accessed on 4 June 2020)

5. Main Statistical Office.

https://stat.gov.pl/download/gfx/portalinformacyjny/pl/defaultaktualnosci/5497/2/8/1/spoleczenst wo_informacyjne_w_polsce_w_2018_roku.pdf (accessed on 4 June 2020)

6. Polak P, Świątkiewicz-Mośny M, Wagner A. Much Ado about nothing? The responsiveness of the healthcare system in Poland through patients' eyes. Health Policy. 2019;123(12):1259-1266. doi: 10.1016/j.healthpol.2019.09.011.

7. Dela R, Dubas-Jakóbczyk K, Kocot E, Sowada C. Improving oncological care organization in Poland-The 2015 reform evaluation in the context of European experiences. Int J Health Plann Manage. 2019; 34(1): e100-e110. doi: 10.1002/hpm.2635. 